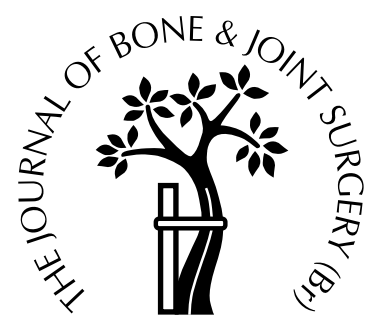

\title{
The posterolateral approach to the distal humerus for open reduction and internal fixation of fractures of the lateral condyle in children
}

\author{
N. Mohan, J. B. Hunter, C. L. Colton \\ From the University Hospital, Nottingham, England
}

\begin{abstract}
O ur study describes a posterolateral approach to the distal humerus for open reduction and internal fixation of displaced fractures of the lateral condyle. A total of 20 patients had open reduction and internal fixation over a four-year period using this approach, and at a mean follow-up of 12 months had full union, range of movement and no complications, either clinical or radiological. This approach is well suited to the exact visualisation and accurate reduction of this difficult fracture with minimal dissection of tissues.
\end{abstract}

J Bone Joint Surg [Br] 2000;82-B:643-5.

Received 3 August 1999; Accepted after revision 31 January 2000

The lateral (Kocher) approach has been traditionally recommended for open reduction and internal fixation (ORIF) of fractures of the lateral condyle of the humerus. ${ }^{1,2}$ The drawbacks of this approach are that the incision is centred over the site of maximum swelling and the approach passes through the damaged tissues to expose the condyle, while the fracture lies in a plane away from the view of the surgeon. It is difficult to visualise accurate reduction. The joint is seen only by increased dissection over the anterior and posterior surfaces of the condylar fragment theoretically impairing the already precarious local blood supply. The posterior approach, dividing the tricipital aponeurosis, has been advocated by many authors ${ }^{3-7}$ mainly for supracondylar fractures, but also for fractures of the lateral condyle. It is based more on the medial aspect of the joint. Identification and isolation of the ulnar nerve are necessary steps and together with division of the tricipital aponeurosis, which do not offer any real advantage in access to the

N. Mohan, MS Orth, Orthopaedic Registrar

J. B. Hunter, FRCS Ed (Orth), Consultant Orthopaedic Surgeon

C. L. Colton, FRCS Ed (Orth), Consultant Orthopaedic Surgeon

Department of Trauma and Orthopaedics, Queen's Medical Centre, University Hospital, Nottingham NG7 2UH, UK.

Correspondence should be sent to $\mathrm{Mr} \mathrm{N}$. Mohan at the Institute of Orthopaedics, Brockley Hill, Stanmore, Middlesex HA7 4LP, UK.

(C)2000 British Editorial Society of Bone and Joint Surgery 0301-620X/00/510435\$2.00

VOL. 82-B, No. 5, JULY 2000 lateral side of the joint. Our study describes the posterolateral approach and presents a retrospective series of 20 patients on whom this was used.

\section{Patients and Methods}

We reviewed 20 children with displaced fractures of the lateral condyle treated between 1993 and 1996 (Fig. 1). Their mean age was seven years (2 to 13). The fractures were classified using the Milch classification ${ }^{8}$ as type I $(n=2)$ when the fracture line traversed the ossific nucleus of the lateral condyle or type II $(n=18)$ when it exited through the trochlea. All the patients were operated on within 24 hours of injury and an accurate reduction was achieved. The fractures were fixed with a cancellous screw though the metaphyseal fragment. ${ }^{9}$ A Kirschner wire was used to augment the fixation when the metaphyseal fragment was small. Immobilisation was used for a period of four to six weeks, and the final outcome assessed at a mean of 12 months (6 to 24) after the operation.

Operative technique. The patient is placed supine or in the lateral position with the arm supported and the forearm hanging freely. An incision is made posterolaterally starting at the distal third of the humerus and continuing for a short distance past the olecranon, deviating radially (Fig. 2). After dissection through the subcutaneous tissue, the fascial layer covering the triceps is incised at its lateral border. The intermuscular plane between the triceps and brachioradialis is then utilised to gain access to the distal humerus, retracting the lateral border of the triceps medially. Minimal softtissue dissection is required, and the fracture is visualised directly (Fig. 3).

The joint line is seen well, and an accurate reduction may be achieved with the fracture under direct vision. A Kirschner wire is used to hold the reduction temporarily, and a cancellous screw inserted across the fracture (Fig. 4). In some cases a small-fragment cannulated screw is used (Stratec, Welwyn, UK). The metaphyseal portion of the fragment is fixed to the distal humerus, as described by Connor and Smith. ${ }^{9}$ The stability of the elbow is tested through its full range of movement. Subcutaneous and skin closure is carried out, and the elbow protected in a plaster backslab or with a collar-and-cuff sling.

After operation the elbow is immobilised for four to six 


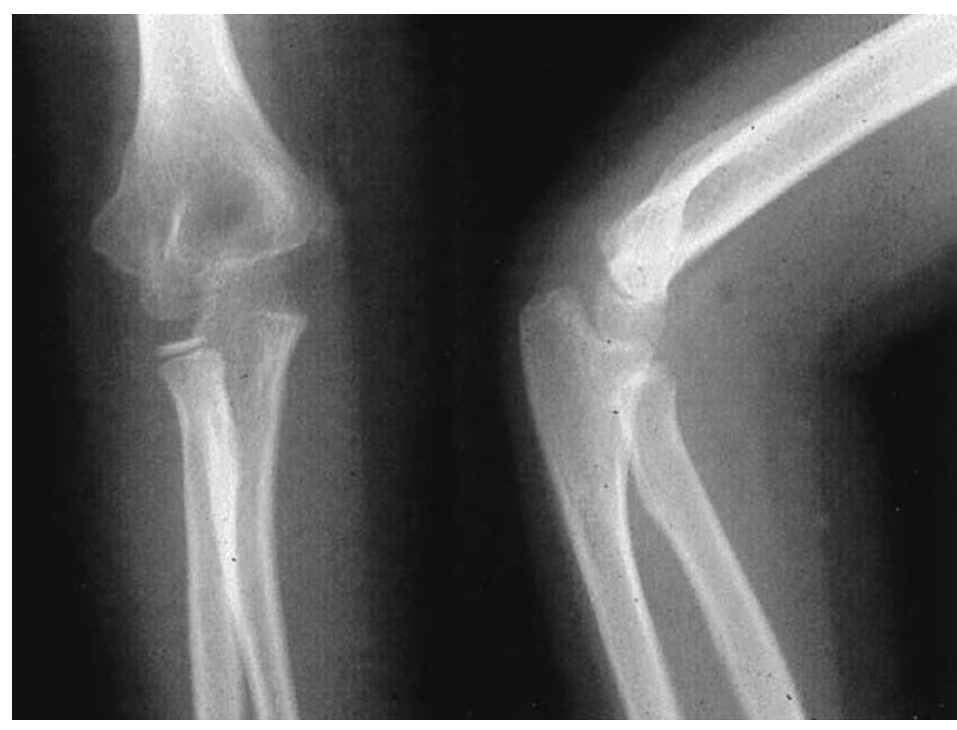

Fig. 1a

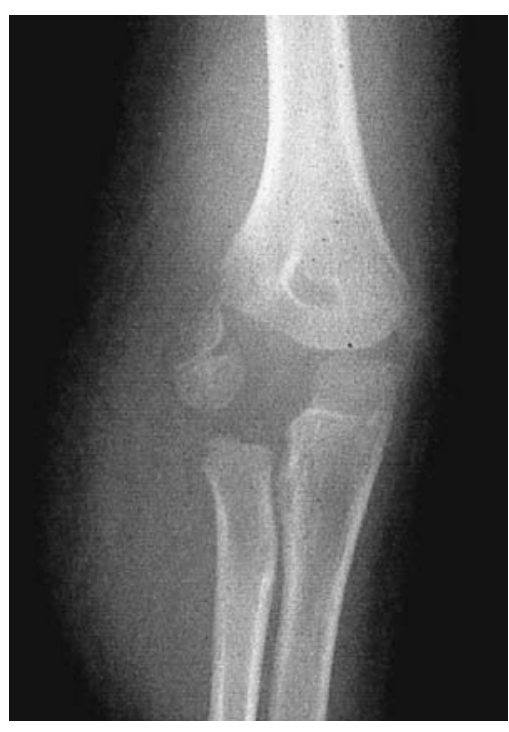

Fig. 1b

Figure 1a - Anteroposterior and lateral radiographs of a fracture of the lateral condyle. Figure $1 \mathrm{~b}-$ An oblique view shows the fracture to be considerably displaced.
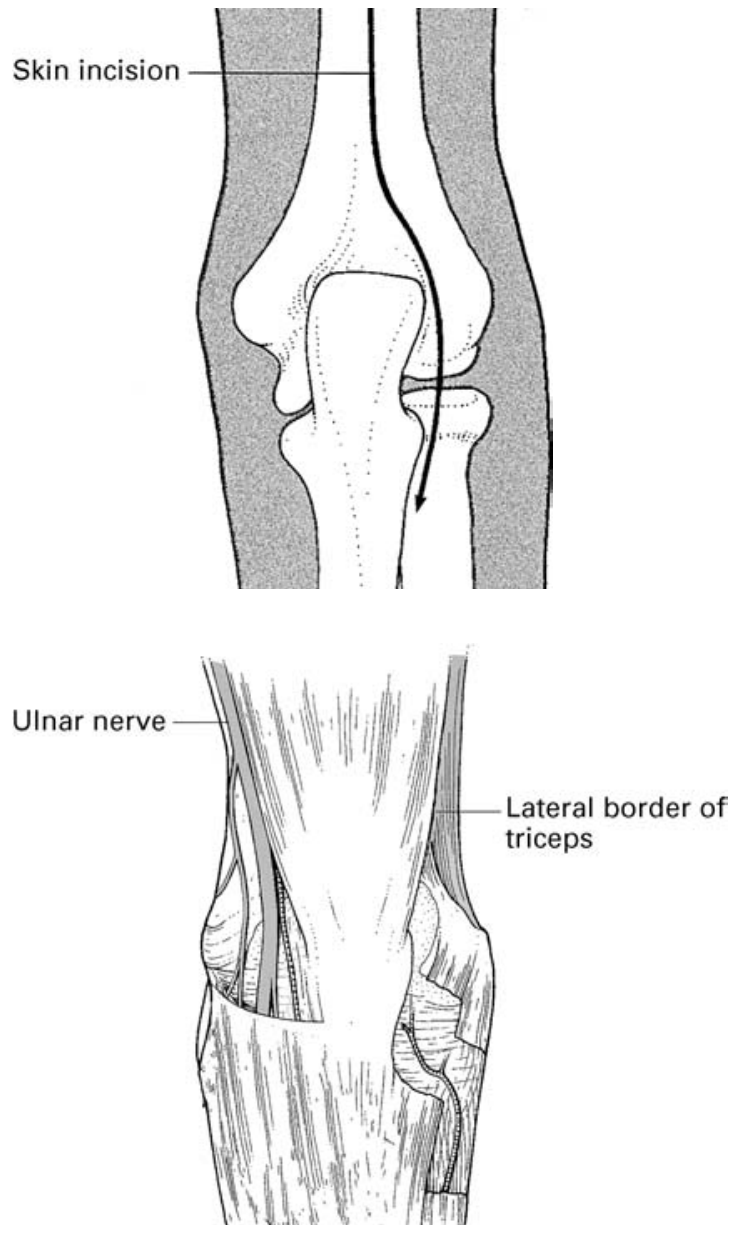

Fig. 3a

\section{Fig. 2}

Diagram showing the skin incision along the lateral border of the triceps, extended across the elbow, deviating radially.

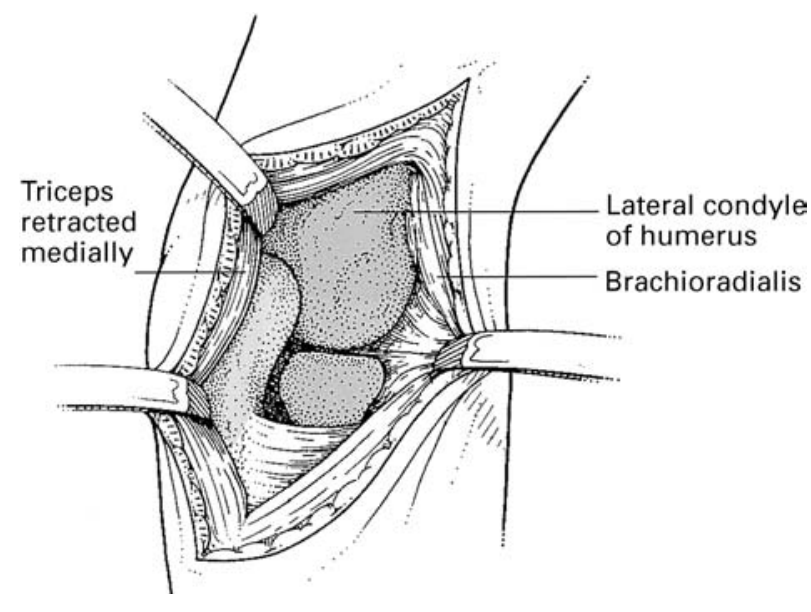

Fig. 3b

Diagrams showing tissue dissection down to the site of the fracture directly exposing the plane of reduction. 


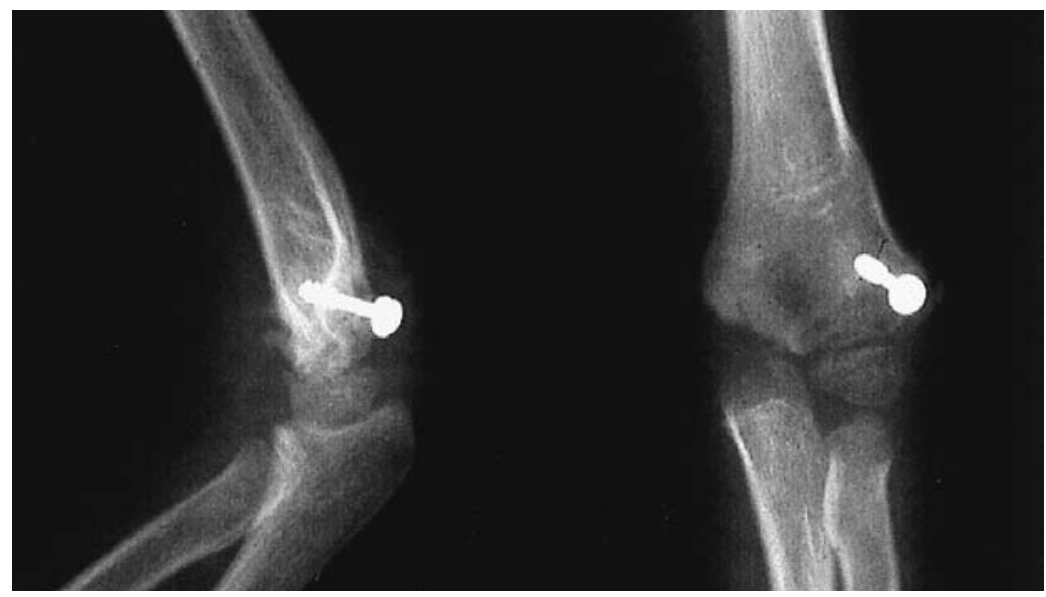

Fig. 4

Lateral and anteroposterior postoperative radiographs showing the posteroanterior orientation of the screw.

weeks. Children usually regain a good range of movement without any need for physiotherapy. Radiographs were taken before and at six weeks, three months and one year after operation.

\section{Results}

The mean follow-up was for 12 months (5 to 24). There were no intraoperative or postoperative complications. All the fractures healed satisfactorily and were united at the time of radiological assessment at three months. There were no angular deformities at review. There were no cases of avascular necrosis, nonunion or epiphyseal overgrowth.

The skin wounds healed well and the cosmetic appearance was acceptable. In all patients there was a full range of movement.

\section{Discussion}

The usually recommended surgical approach to these fractures has been the lateral (Kocher) approach, ${ }^{10}$ although more recently, some authors have used other approaches. $7,11,12$ Our main reservation about the use of the lateral approach has been that it is not well placed for accurate visualisation of the fracture and the joint, which is of great importance to the reduction. By approaching the fracture posteriorly, no anterior dissection is required, thereby maintaining the vascularity of the fragment. The posterolateral approach has been condemned for fractures of the lateral condyle ${ }^{2}$ because most of the blood supply to the distal humerus has been shown to enter posterolaterally. ${ }^{13,14} \mathrm{We}$, however, did not encounter avascular necrosis in any of our patients. The screw is passed at right angles to the plane of the fracture with the reduction under direct view at all times, and the joint line is accurately reconstructed.

The scar is posterior and away from direct view, unlike lateral or anterior scars around the elbow, making it cosmetically more acceptable.
We have found the posterolateral approach to be a safe method of open reduction and internal fixation of these difficult fractures. The functional and cosmetic results are satisfactory. We recommend it as a suitable alternative to the lateral (Kocher) approach.

No benefits in any form have been received or will be received from a commercial party related directly or indirectly to the subject of this article.

\section{$\underline{\text { References }}$}

1. Crenshaw AH Jr. Surgical techniques and approaches. In: Canale ST, ed. Campbell's operative orthopaedics. Vol. 1. 9th edition. St Louis: CV Mosby, 1998:29-142.

2. Wilkins KE, Beaty JH, Chambers HG, Toniolo RM. Fractures and dislocations of the elbow region. In: Rockwood CA Jr, Wilkins KE, Beaty JH, eds. Fractures in children. Vol. 3. Philadelphia: LippincottRaven, 1996:653-904.

3. Gruber MA, Hudson OC. Supracondylar fractures of the humerus in childhood: end-result study of open reduction. J Bone Joint Surg [Am] 1964;46-A:1245-52.

4. Hart GM, Wilson DW, Arden GP. The operative management of the difficult supracondylar fracture of the humerus in the child. Injury 1977;9:30-4.

5. Kasser JR, Richards K, Millis M. The triceps-dividing approach to open reduction of complex distal humeral fractures in adolescents: a Cybex evaluation of triceps function and motion. J Pediatr Orthop 1990;10:93-6.

6. Sibly TF, Briggs PJ, Gibson MJ. Supracondylar fractures of the humerus in childhood: range of movement following the posterior approach to open reduction. Injury 1991;22:456-8.

7. Gruber MA, Healy WA. The posterior approach to the elbow revisited. J Pediatr Orthop 1996;16:215-9.

8. Milch H. Fractures and fracture dislocations of the humeral condyles. J Trauma 1964;4:592-607.

9. Connor A, Smith MGH. Displaced fractures of the lateral humeral condyle in children. J Bone Joint Surg [Br] 1970;52-B:460-4.

10. Canale ST. Fractures and dislocations in children. In: Canale ST, ed. Campbell's operative orthopaedics. Vol. 3. 9th edition. St Louis: CV Mosby, 1998:2363-536.

11. Blasier RD. The triceps splitting approach for repair of distal humeral malunion in children: a report of a technique. Am J Orthop 1996;25:621-4.

12. Moran MC. Modified lateral approach to the distal humerus for internal fixation. Clin Orthop 1997;340:190-7.

13. Teot L, Gilbert A, Amichot G, et al. Epiphyseal vascularisation during growth: the upper limb. Ann Chir Main 1984;3:237-44.

14. Haraldsson S. On osteochondrosis deformans juvenilis capituli humeri including investigation of intra-osseous vascularity in distal humerus. Acta Orthop Scand 1959; suppl. 38. 